\title{
Mineralogical studies of plagioclase feldspar in Kadavur Anorthosite Complex, Tamilnadu
}

\author{
M. Vinoth Kumar, R. S. Kumar*, K.Rajaprian, Kuldeep Singh \\ Department of Earth sciences, Annamalai university, Chidambaram, TN India \\ *Corresponding author E-mail: rskgeo@gmail.com
}

\begin{abstract}
The differences in the type of plagioclase twinning in igneous and metamorphic rocks are described. Plagioclase twins are divided, from a Petrological point of view, into the c-twin and the A-twin. Frequencies of the twinned plagioclase and twin types in various endogenous rocks are described and the genesis of the $\mathrm{C}$-twin which characterizes the volcanic and plutonic rocks is interpreted. Lastly, a plagioclase twin method for determining the origin of various granitic rocks is proposed and discussed. Extremely dense Carlsbad twins at the unit-cell scale indicate that additional energy caused by the Carlsbad twin boundaries in highly disordered anorthite is lower than that caused by albite twin boundaries. We propose that for anorthite with an initially disordered structure the total energy induced by Carlsbad twinning is lower than that caused by albite twinning and higher than that caused by albite twinning in anorthite with an initially ordered structure.
\end{abstract}

Keywords: Mineralogical Studies, Plagioclase Twinning Law, Kadavur Anorthosite Complex.

\section{Introduction}

Twinning is common in feldspars. Twins can form during crystallization, cooling, deformation, or combinations thereof (Buerger 1945). There are many types of twins in feldspars and their details vary. Here, we consider Carlsbad, Carlsbad-albite, and albite twins that formed during crystallization. Carlsbad and Carlsbad-albite twins are abundant in plagioclase from volcanic and hightemperature plutonic rocks and rare in metamorphic rocks, whereas albite twins commonly occur in triclinic feldspar (Gorai 1951) Carlsbad and Carlsbad-albite twins have been called complex twins or C twins by Gorai (1951), who suggested that the frequency of the $\mathrm{C}$ twins in calcic plagioclase may indicate the crystallization temperature of the feldspar crystals and their initial structural states (Al-Si order). Theoretical studies have shown that $(010)$ is a reasonable composition plane for both Carlsbad and Carlsbadalbite twins, and that the composition plane does not produce serious lattice misfit between neighboring twin lamellae (Dowty 1980; Wooster 1981). According to the above interpretation the writer has tried to deduce the mechanism of plagioclase crystallization in some rocks formed near the boundary between magmatic and metamorphic processes and from this also to postulate the environmental conditions under which these rocks were formed. In the present study detailed mineralogical and Twin studies were carried out to understand The area occupies 50 square kilometer roughly and lies between the latitudes $10^{\circ} 30^{\prime}$ and $10^{\circ} 35^{\prime}$ and between the longitudes $78^{\circ} 5^{\prime}$ and $78^{\circ} 15^{\prime}$. It forms the parts of the Survey of India toposheet No.58 J/2. The study area Kadavur located in Karur district, Tamilnadu (Fig 1).

\section{General geology}

The Kadavur Meta - igneous complex is exposed amidst a catazonal of high grade supracrustal sequence belonging to the Eastern Ghats precambrain belt. The supracrustal litho logics preserve evidence of polymetamorphic history and are represented by,

1) Quartzite: Quartz- schists and feldspathic quartzites: Quartzsillimanite, biotite muscovite-plagioclase -orthoclase (magnetite-zircon- hornblende- blades ilmenite-chlorite)

2) Calc granulite: Hedenburgite-plagioclase - scapolite-calcite(garnet-sphene-apatite-quartz- hornblende-chlorite)

3) Amphibolite: Hornblende-plagioclase-quartz (cumingtoniteactinolite epidote-zoisitc sphene - scapolite-chlorite).

Quartzites alternating with quartz-schists and minor feldspathic quartzites are by far the most dominant supercrustal lithology and along with minor intercalations of calc-silicate rocks (calcgranulites) from the metasedimentary component of the supracrustal sequence. Amphibolites, though confolded with the metasedimentary sequence there by forming an integral part of the supra-crustal sequence, possibly represent mafic flows, or sills as these occur as layer-like bodies in quartzites. They have major element chemistry comparable to Theolitic basalts. The gabbroanorthosite complex shows abundant xenolithic inclusions of the host rocks including amphibolites (Sarkar 1987). 


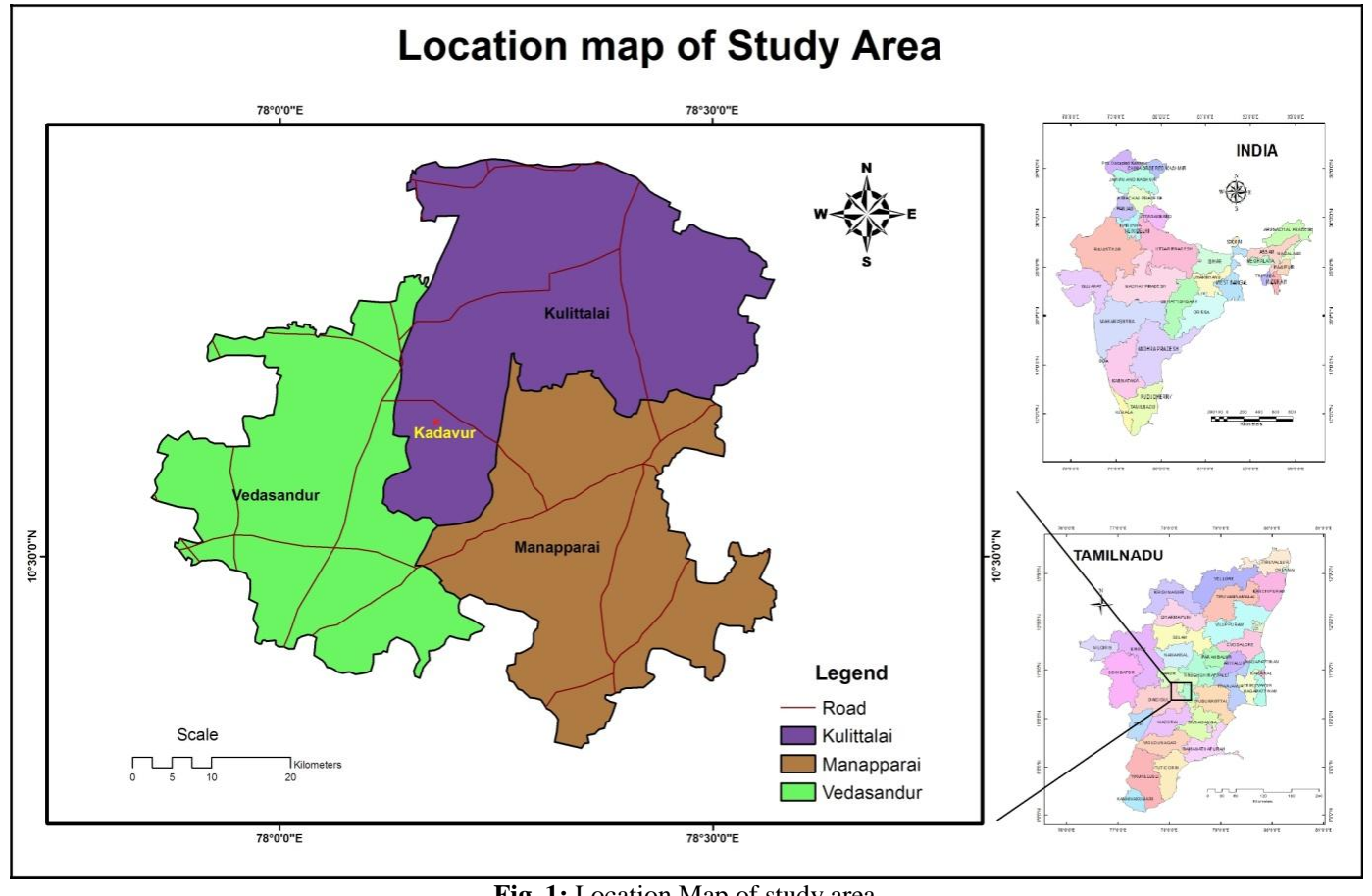

Fig. 1: Location Map of study area

\section{Petrography \& mineralogy of anorthosites}

Based on the field observation and megascopic studies in the field and in the hand specimen of the anorthosites and related rocks, typical varieties of anorthosites and related rocks representative samples were selected and more than 25 thin sections were prepared from the specimens collected from the different locations in and around from the Kadavur area. On the basis of a careful and detailed study of all the sections prepared the petrographic descriptions are given below.

\subsection{Anorthosites}

The anorthosites are leucocratic and medium to coarse rocks. The mafic content of the rock is variable though in smaller proportions. In the core of the anorthosite mass, the mafic content is almost nil. Towards the margin even within anorthosite the mafic constituents are well recognizable in the hand specimens. In some specimens, two distinct type of plagioclase can be noted in anorthosites as coarse blue grey plagioclase crystals are set in a matrix of dull white fine grained plagioclase. This imparts the rocks to a porphyritic appearance. The coarse crystals range from a quarter centimeter to two centimeter in size. They strikingly exhibit play of colours in outcrops and in hand specimens. The medium grained anorthosites are dull and whitish, creamy in colour. Generally the mafic occurs as medium size grains. In some places, however there is coarse development of hornblende crystals which measure up to 2 to $8 \mathrm{~cm}$ in size. In the outcrops, there are occasional mafic clots in the rocks can be observed. The megascopic observation of anorthosites in outcrop and in hand specimen based on field colour and grain size, it can be well identified as leucocratic and mesocratic anorthosite. Both the anorthosites can be classified on the basis of grain size coarse grained and medium grained varieties also.The leucocratic anorthosites are light in colour and are chiefly composed of white to light grey coloured plagioclases. They occur as massive mass with transition to mesocratic anorthosites are dark grey in colour. Its mesocratic nature is due to the presence of dark grey coloured plagioclase. Except for the mesocratic nature they do not show much variation in textural and mineralogical characteristics. The anorthosites on the basis of grain size it can be distinguished as coarse grained to medium anorthosites. Coarse plagioclases strikingly exhibit play of colours in outcrops and hand specimens. Generally mafic are of medium grain size. Clinopyroxenes from major mafic in anorthosites. Orthopyroxene hypersthenes occur as discrete plates rarely.

\subsection{Noritic Anorthosites}

These are medium grained rocks with cumulate fabric which occur transitional to pure anorthosites. They are largely composed of white and grey plagioclase feldspar plates ranging from $0.5 \mathrm{~mm}$ to $4 \mathrm{~mm}$ in length. In thin sections it shows typical igneous equilibrium texture. It is composed of plagioclase 'a' $55-58$, orthopyroxene with enstatite molecules 40 to 45: few grains of clinopyroxene, hornblende and scapolite as alteration product from pyroxenes and plagioclases. Plagioclase is the predominating mineral forming about $85-95 \%$ of the rock. It occurs mostly as subhedral grains. Its "An" content varies from $58-65 \%$. These values are relatively higher than pure anorthosite. Plagioclase grains show prominent cataclastic effects by undolose extinction, wedging and bedding of twin lamellae. These feldspars have turbid appearance and carry oriented rod shaped inclusion of opaques. Peripheral granulation attributable to protoclastic deformation is exhibited by many of the large plates of feldspars.

\subsection{Gabbroic Anorthosite}

These are medium to coarse grained rocks with less leucocratic nature than the anorthosites due to their higher ferromagnesian content. They show in the field gradational changes into pure anorthosites and are genetically related to the latter. They show blotchy appearance due to clustering of granular aggregates of hornblende in a matrix of plagioclases in some sections. In thin sections these rocks preserve cumulate texture to a greater extent.

\subsection{Anorthositic gabbro}

These are medium to grained rocks and display, the typical gabbroidal texture. The plagioclase constitutes 65 to $75 \%$ of the rocks. The plagioclases are found to have the compositions of $\mathrm{An}_{50-55}$. In thin sections they show subophitic relations with the pyroxenes (Fig.2). The feldspars are turbid due to the presence of dust like inclusions of ores and granules of pyroxenes. The mafic minerals present are essentially pyroxenes. The clinopyroxene is the chief mafic mostly occurs as interstitial phase in the midst of plagioclase and also as homogenized coarse plates. It is pale green and 
also shows islands of orthopyroxene and oriented inclusions of iron oxides.

\subsection{Gabbros}

These are melanochrotic equigranular medium grained rocks. These are gradational to leucogabbros (anorthositic gabbros and gabbroic anorthosites) and show crude foliation in outcrops. In thin section exhibits typical gabbroidal texture. These are essentially composed of plagioclases, clinopyroxenes and orthopyroxene with fair amount of ores. The relative proportions of these essential minerals show wide variation from plagioclase dominated varieties to mafic dominated varieties and either as clinopyroxene dominated or orthopyroxene dominated varieties.

\section{Twinning in feldspar}

The feldspar is showing very common twinning. The usual type in monoclinic feldspar is known as Carlsbad twinning, other types include the Manebach and Baveno in triclinic feldspars the albite type of twinning is present and other types are not rare, especially the pericline and Carlsbad.

- Twinning axes either lie in the composition face or normal to it, leading to the classification parallel, complex or normal.

- In a parallel or complex twin the relative birefringence colours of adjacent lamellae change under the following condition of rotation. The composition face made vertical and parallel to a nicol and rotated on a horizontal axis normal to it. Under the same conditions birefringence colours of the adjacent lamellae of a normal twin also change, but they rise and fall together. This information reveals the exact position of a normal twinning axis and limits the parallel or complex twinning axis to one plane.

- In parallel or complex twins the change in interference colour of adjacent lamellae may be used to locate the twinning axis. When the interference colour of the adjacent lamellae are identical the twinning axis is either horizontal or vertical assuming as in 2 above that the composition face is rotated in a vertical position on a horizontal axis which is perpendicular to a nicol. The same is true of the composition face is $45^{\circ}$ to a nicol.

- If a parallel or complex twinning axis is vertical, both lamellae extinguish simultaneous. If horizontal, the adjacent grain extinguish alternately on rotation of the microscope stage.

\subsection{Carlsbad twin}

In Carlsbad twinning the twins are united usually on 010 planes, parallel to the vertical axis, while the twinning axis may be considered to be "c", or a line normal 100. In thin section the Carlsbad twin and the 010 cleavage in one part is parallel, while in the other part with the basal cleavage form oblique angles with one another. If the section is normal to 010 , the 001 clearages will be exactly or very nearly at right angles (Table 1 ).

\subsection{Manebach twin}

Manebach twins have the basal plane as the twinning plane and also usually as the composition face. It is an irregular twin of orthoclase. The twin plane is (001) face and the twin axis is b-axis. The 001 cleavages of one part are parallel to the same cleavages of the other part. The same is true of 010 cleavage of the feldspar in monoclinic.

\subsection{Baveno twin}

In Baveno twins the twinning axis is normal to 021 which is the composition face; such twins are elongated parallel to an axis and often flattened parallel to 001 . In the absence of flattening they are nearly square in cross section, since $001 \wedge 021$ are nearly $45^{\circ}$, being $44^{\circ} 56^{\prime}$ in orthoclase and $46^{\circ} 46^{\prime}$ in albite. Sections across such twins present square or rhombic outline, the clearage being parallel to the sides and the twinning line being a diagonal from corner to corner. Albite and pericline twins are impossible in monoclinic crystals but are very important in plagioclase.

\subsection{Albite twin}

In albite twinning both the composition face and twinning plane are 010 . This type of twinning is nearly always polysynthetic and lamellar, producing striations on 001 parallel to 010 . It would be perfectly parallel growth in orthoclase. Albite twinning is characteristic of plagioclase.

\subsection{Pericline twin}

In pericline twins the twinning axis is the axis $b$, while the composition face is the rhombic section, which is the section made by a plane passing through the crystal parallel to the axis $b$, in such a direction that it makes equal angles with 110 and 110. In 010 these twinning bands vary from parallel to the basal cleavage. Except rarely in albite, pericline twinning is multiple, fine lamellar and invisible without the microscope. Orthoclase often occurs in simple twins but never in polysynthetically twinned in two directions, giving a fine grating structure in crossed nicols. Plagioclase is nearly always multiply twinned on the albite (or pericline) law.

\subsection{Normal twins}

In which the twinning axis is normal to the composition face, which is an important crystal face, namely (010) in albite twinning (001) in Manebach twinning, (021) in Baveno twinning and (100) in twinning expected but not yet found.

\subsection{Parallel twins}

In which the twinning axis is parallel to the composition plane, which may be a crystal face or very notably from such a face.

\subsection{Complex twins}

It consists of aggregates showing both normal and parallel twins having the same composition face. A crystal may have Carlsbad twin and also albite twinning the composition face being (010) for each, the aggregate is called 'complex' twin.

\section{Twin law studies}

The twinning law observed in plagioclase is empirically useful for geological and Petrological discussion though the correlation between twinning laws and their formation mechanism (Smith, 1974). The frequency of various plagioclase twinning laws has become a tool to discriminate different classes of rocks (Gorai, 1951; Suwa, 1956; Tobi, 1962). The discrimination by plagioclase twinning laws has been established during the last half century, but it must be revised with the background of new geological and tectonic schemes (Tobi, 1987; Takahashi, 1995). For this revision, a practical and reliable method to identify the plagioclase twinning laws under the microscope will be prepared for people who are not familiar to optical mineralogy. There are multiple opinions regarding the genesis of plagioclase twinning and the frequence of different twin laws in relation to chemical. Structural and environmental factors and its significance in petrogenesis. 

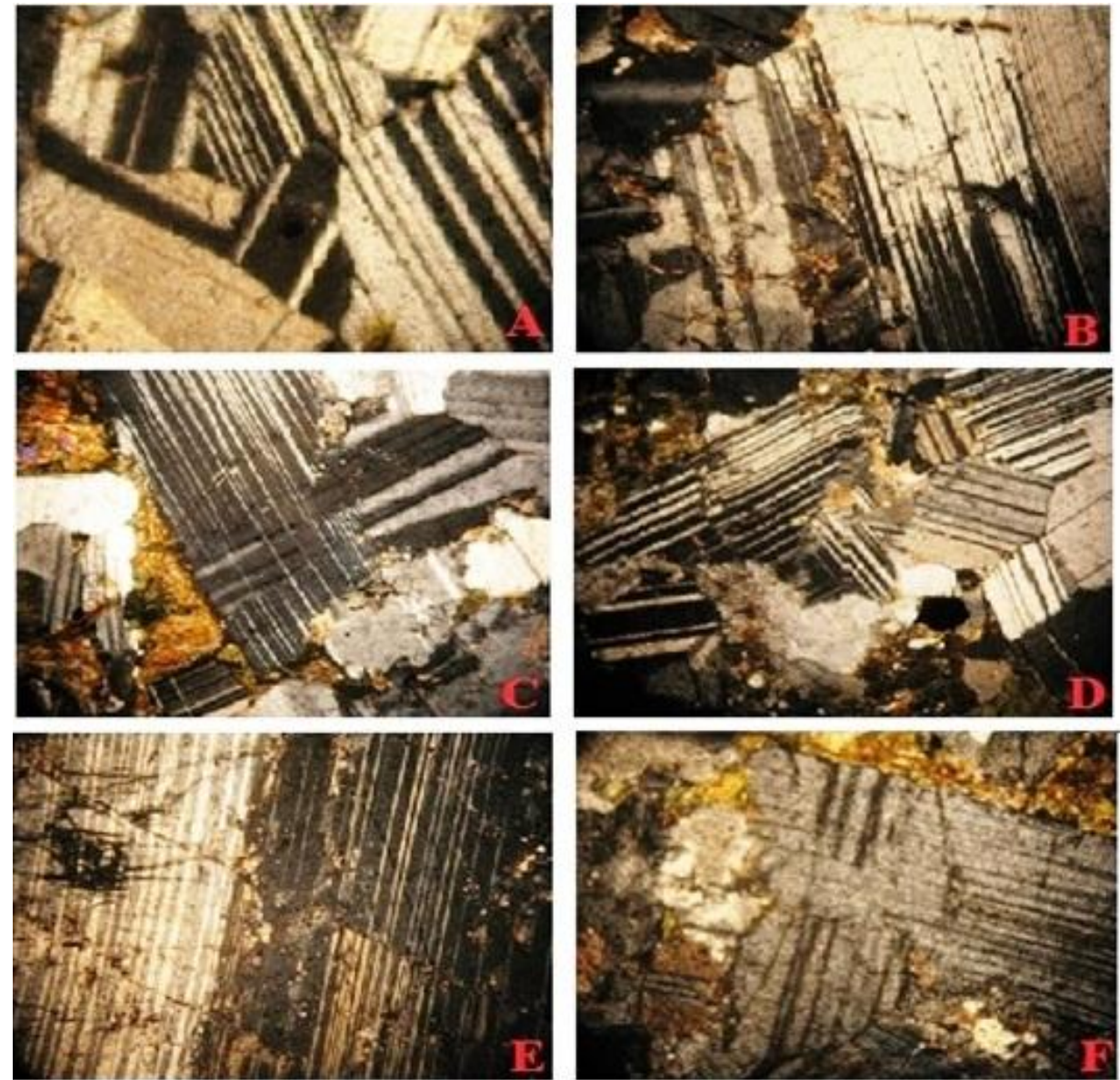

Fig. 2:

A. Microphotograph of Anorthosite showing the Plagioclase exhibits twinning Penetration Twins. B. Microphotograph of Anorthosite showing the Plagioclase exhibits twinning Polysynthetic Twins.

C. Microphotograph of Anorthosite showing the Plagioclase exhibits twinning Penetration Twins.

D. Microphotograph of Anorthosite showing the Plagioclase exhibits twinning Complex Twins.

E. Microphotograph of Anorthosite showing the Plagioclase exhibits twinning Penetration Twins.

F. Microphotograph of Anorthosite showing the Plagioclase exhibits twinning Polysynthetic Twins.

Table 1: Twinning of feldspar and twin laws

\begin{tabular}{|c|c|c|c|c|}
\hline Name & Designation & Composition face & Axis & Description \\
\hline & & Normal twin laws & & \\
\hline Albite & $(010)$ & $(010)$ & $\perp(010)$ & Usually Multiple \\
\hline Manebach & $(001)$ & $(001)$ & $\perp(001)$ & Usually Simple \\
\hline Baveno & $(021)$ & (021) & $\perp(021)$ & Usually Simple and relatively uncommon \\
\hline & & Parallel twin laws & & \\
\hline Carlsbad & [001] or c & $(010)$ & $\mathrm{c}$ & Usually Simple \\
\hline Acline & {$[010]$ or $b$} & $(001)$ & $\mathrm{b}$ & \\
\hline Pericline & {$[010]$ or $b$} & Rhombic Section & $\mathrm{b}$ & Commonly multiple \\
\hline \multirow[t]{2}{*}{ Ala b } & [010] or a & $(010)$ & a & \multirow[b]{3}{*}{ Commonly multiple } \\
\hline & & Complex twin laws & & \\
\hline Albite-Carlsbad & $\perp_{[001]}$ in $(010)$ or $\perp \mathrm{c}$ in $(010)$ & $(010)$ & $\perp \mathrm{c}$ & \\
\hline Albite - Ala & {$[100]$ in $(010)$ or $\perp$ a in $(010)$} & $(010)$ & $\perp \mathrm{a}$ & Commonly multiple \\
\hline
\end{tabular}

\subsection{Plagioclase twins}

The present study has been under investigation for the purpose of determining the Petrological significance of plagioclase twining in anorthositic rocks of, Kadavur anorthosite complex in Tamilnadu, based on the morphological observation of the twinned plagioclase in the ordinary Petrological microscope. Gorai (1951) identified four different kinds of twins in plagioclase with specific shape and orientation and combination of twin lamellae (Fig.3).

\subsection{Genesis of twins}

Twins form by several mechanisms whose nature and frequency is not always clear from study of the morphology. Consequently the nomenclature can be misleading unless the limitations are appreciated. Theories of the various processes for generating twins are rudimentary. The plagioclase twinning law is characterized by the composition plane (here in after $\mathrm{CP}$ ) and direction of the symmetry axis (here in after SA), that is the twin axis. The SA is the same as a two-fold axis. About 20 twinning laws have been defined (e.g., Smith and Brown, 1988), but some are not known in nature or are undistinguishable from other laws. Tobi (1987) referred to ten twinning laws. Frequent plagioclase twinning laws are albite, albite-Carlsbad, acline and Pericline laws. Common but not frequent laws are Carlsbad, Ala A and Baveno laws. Rare laws 
are Ala B, albite-Ala B and Manebach laws. The Ala B and albiteAla B twins may not exist in nature. The albite-Ala B and albite laws become optically identical in oligoclase and andesine compositions (Suwa et al., 1974). Smith (1974) and Tobi (1987) inferred that most (or all) of the albite-Ala B twinning law described in previous reports should be the albite law. The rhombic section, $\mathrm{CP}$ of the Pericline twinning law, coincides with (001), CP of acline twinning law, in oligoclase to andesine. Therefore the Pericline and acline laws are identical in this composition. Smith (1974) doubted the Ala a law for the twinning law with CP (001), but Tobi (1987) insisted that the Ala A law is more common than the Manebach law. A thin acline lamella that was found quite near the Ala composition plane should have a Manebach symmetry relation to the opposite Ala individual. Tobi (1987) calls it a "pseudoManebach" law. Based upon the above mentioned review, there are eight plagioclase twinning laws that we need to understand albite, Carlsbad, albite-Carlsbad, pericline, acline, Ala A, Manebach and Baveno laws. These twins are classified into three types, normal, parallel and complex twins (Fig.4) based upon the relationship between $\mathrm{CP}$ and SA. The normal twin is defined as the twin whose SA is normal to the CP. The parallel law is the law whose SA is a crystallographic axis lying in the CP. The complex law is the law whose SA lies in the CP normal to a crystallographic axis. The complex law can be thought as a joint operation of the normal and the parallel laws. The above mentioned eight plagioclase twinning laws are summarized in Table 2 based on the definition of the CP and SA.

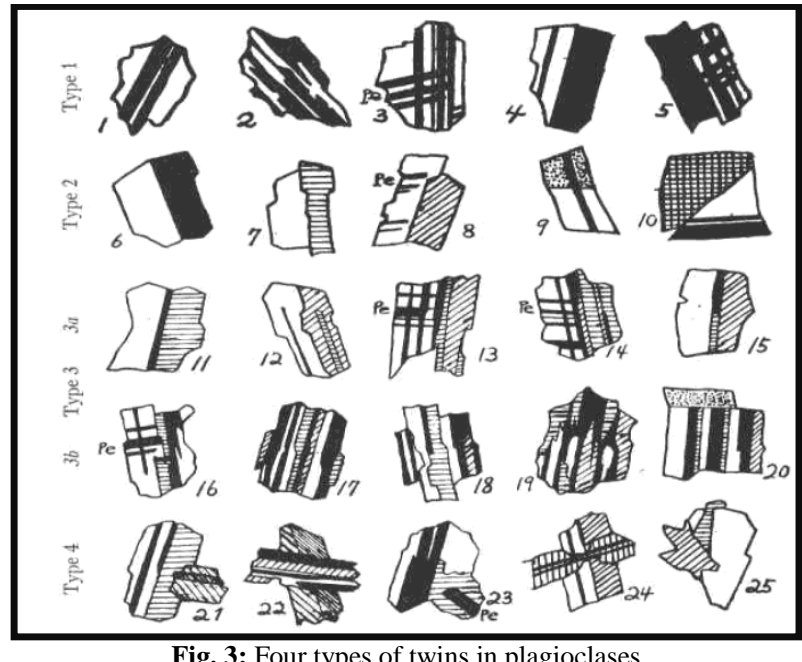

Fig. 3: Four types of twins in plagioclases

Type 1: Polysynthetic twins (1, $2 \& 4)$ and their modification (3 \& 5)

Type 2: Simple twins (6\&7) and modifications $(8,9 \& 10)$.

Type 3: Complex twins (6\&7) and their modifications: this is subdivided into 3a (11-15) 3B (16-20).

Type 4: Penetration Twinning (21-25).

\subsection{Twinning mechanisms and nomenclature}

Burger (1945) classified twins under the categories growth, transformation, and gliding as follows:

Table 2: Classification of twinning in feldspars

\begin{tabular}{|c|c|c|c|}
\hline Composition plane (CP) & Normal law & $\begin{array}{l}\text { Parallel law } \\
\text { Symmetry Axis (SA) }\end{array}$ & $\begin{array}{l}\text { Complex law } \\
\text { Symmetry Axis (SA) }\end{array}$ \\
\hline (010) (=Cleavage) & Albite // & Carlsbad [001] & $\begin{array}{l}\text { Albite-Carlsbad } \\
\text { normal to [001] in [010] }\end{array}$ \\
\hline$(001)(=$ Cleavage $)$ & Manebach** & $\begin{array}{lr}\text { Acline*// } & {[010]} \\
\text { Ala A** } & {[100]}\end{array}$ & ------------ \\
\hline $\begin{array}{l}\text { Rhombic section } \\
\text { (021) diagonal to cleavages }\end{array}$ & Baveno & Pericline* // [010] & ------------ \\
\hline
\end{tabular}

1) Growth twinning is caused by an accidental departure from equilibrium during growth and is favored in the nuclear stage especially under conditions of supersaturating.

2) (Transformation twinning is a consequence of a high-low inversion.

3) Glide twinning is caused by a specific of structural shear in plastic deformation.

The mechanisms for twinning during crystal growth can be envisaged, nucleation error, epitaxial inheritance and synneusis. For the first mechanism, atoms adopt incorrect positions in the nucleus such that two parts from with a common surface. Although such error should occur most easily for the first nucleus, error may also occur during secondary such that they become attached on external faces with lattice rows in common. Burger had not thought of the concepts of epitaxial inheritance and synneusis and his growth twin strictly includes only the nucleations -error type. Here the term growth twin will cover all three mechanisms. Transformation twins (first characterized by Bernal, 1938) pose on problems when the transformation is isochemical and structurally coherent, such as the sanidine-An orthoclase inversion.

These transformation twins are epitaxial in symmetry. Problems arise when the transformation involves such high activation energy that external physical and chemical factors influence the product. Thus the sanidine microcline inversion is complicated seriously by chemical migration and external shearing stress. Glide twinning by mechanical deformation in theory may be extremely simple, involving easy atomic movements with strict preservation of common crystallographic elements: e.g. as in mechanical deformation of anorthosites and high albite. However, if high activation energy is involved as in ordered plagioclase of intermediate composition, the product may be influenced by external chemical and physical factors. Even though an epitaxial nucleation is involved, the term glide twinning is still Mechanical twinning is used synonymously with glide twinning. Another approach to twin nomenclature uses the term primary and secondary which imply a time relation between the twinning and the original coalescence of material to form the crystal. Vance considered synneusis (also called combination twinning by Ross (1957) and agglutination twinning by is not a simple growth mechanism, and classified I with secondary twinning. Presumably epitaxial inheritance the time at which twinning took place, syngeusis and epitaxialinheritance twinning are best included with primary twinning. Nucleation on the surface of a growing crystal. Epitaxial inheritance occurs when growth commences on a fragment of existing crystal of different chemical composition such that an existing twin structure is automatically inherited by parallel by growth onto the existing twin units. Synneusis twinning results from floating together of two crystals

Consider now the various processes of twin formation:

1) Nucleation Error in a liquid; the basic processes involved in growth are discussed earlier. The changes of error should be greatest at the time of nucleation because there is no preexisting crystal to act as a template on one side of the nucleus. Subsequently the changes of error should decreases but remain finite. Later twinning during growth may arise in part from mechanical deformation or from synneusis. The process of growth from a liquid involves so many inclusive factors, including surface poisoning by foreign ions and attachment of foreign crystals, that it appears futile to expect high correlations between twin frequency and the temperature of magmatic crystallization, the composition of the host rock, etc. In general, critic features with a high frequency of twinning characterize primary growth from a liquid. 
2) Nucleation Error in a Solid Medium Growth in a solid medium usually occurs at lower temperature than in subject to the isotropic effect of adjacent grains. Perhaps nuclei form epitasially on existing crystal faces. In metamorphism, a mineral may form by recrystallization of other minerals. Alternatively annealing of a mineral assemblage may result in formation of a polygranular aggregate.

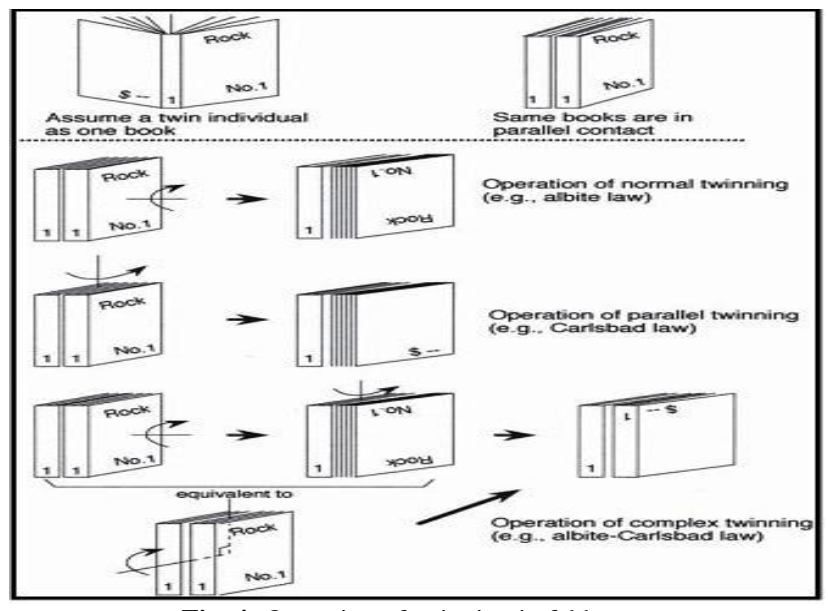

Fig. 4: Operation of twinning in feldspars

\subsection{Twinning mechanisms and nomenclature}

Burger (1945) classified twins under the categories growth, transformation, and gliding as follows:

1) Growth twinning is caused by an accidental departure from equilibrium during growth and is favored in the nuclear stage especially under conditions of supersaturating.

2) Transformation twinning is a consequence of a high-low inversion.

3) Glide twinning is caused by a specific of structural shear in plastic deformation.

The mechanisms for twinning during crystal growth can be envisaged, nucleation error, epitaxial inheritance and synneusis. For the first mechanism, atoms adopt incorrect positions in the nucleus such that two parts from with a common surface. Although such error should occur most easily for the first nucleus, error may also occur during secondary nucleation on the surface of a growing crystal. Epitaxial inheritance occurs when growth commences on a fragment of existing crystal of different chemical composition such that an existing twin structure is automatically inherited by parallel by growth onto the existing twin units. Synneusis twinning results from floating together of two crystals such that they become attached on external faces with lattice rows in common. Burger had not thought of the concepts of epitaxial inheritance and synneusis and his growth twin strictly includes only the nucleations -error type. Here the term growth twin will cover all three mechanisms. Transformation twins (first characterized by Bernal, 1938) pose on problems when the transformation is isochemical and structurally coherent, such as the sanidine-An orthoclase inversion.

\subsection{Syngenusis}

Floating together of crystals of course can occur only in liquid Only those twin laws associated with prominent growth face would be possible by this mechanism (Ross, 1957). Epitaxial Inheritance: This process is difficult to evaluate. In a liquid, it is possible that fragments of pre-existing rock serve as nuclei. In a vein or pegmatite, one feldspar may nucleate on an earlier feldspar produce a twin relation.

\subsection{Transformation twinning}

This type of twinning was demonstrated in the laboratory for high albite. Inversion from monoclinic symmetry produces crosshatched Albite and Pericline twinning in the low-temperature triclinic form. Whether any natural plagioclase shows transformation twinning is doubtful. Sodic plagioclase from volcanic rocks tend to contain at least $10 \%$ of the An and Or molecules. The intersection of the monoclinic-triclinic inversion curve with the dry solidus runs approximately forms An11 diagonally into the ternary system. Smith and Mac-Kenzie (1958) distinguished plagioclase form an orthoclase on the basis that the former did not grow with monocline symmetry. Hence transformation twinning by definition should not occur in plagioclase.

\subsection{Mechanical twinning}

The claimed that glide twinning in feldspars should be confined to those specimens in whom no topologic change of $\mathrm{Al}$ and $\mathrm{Si}$ atoms was required, but he did not consider plagioclase of intermediate composition. A suggested that high atoms are disorder and topologically equivalent. For low plagioclase, the situation should be complex. Peristerite contains low albite topologic pattern blocks glide twinning. Intermediate plagioclase may contain domains similar to low albite and anorthite set in disordered matrix. Smith and Ribbe suggested that the domains of low albite formed only in a late stage of the ordering process. Because the with glide twinning, partly disordered matrix are topologically compatible twinning. Borg and Heard were able to include twinning in ordered plagioclase only at high temperature and pressure. Possibly disordering accompanied the twin process.

\section{Conclusion}

The Petrography of the Anorthosite and related rocks of describe on the basis of the relative model minerals assemblages following the IUGS classification as Anorthosite, Noritic Anorthosite, Gabbroic Anorthosite, Leuco Gabbro, Anorthositic Gabbro/Norites/Ferro Gabbro and oxide rich pyroxenites. The Anorthosite generally exhibits hypidiomorphic texture and some region interlocking texture. From the present study the following conclusion can be drawn.

1) The feldspars in the study area are dominantly composed of plagioclase feldspars.

2) These plagioclase feldspars exhibits very common twinning, generally polysynthetic twinning.

3) The Anorthositic rocks of the study area are composed of plagioclase feldspar with a content range from 55-90.

4) Twinning axis either lie in the composition face or normal to it, leading to the classification as parallel, complex or normal.

5) In a parallel or complex twins the relative birefringence colour of adjacent lamellae change under the following condition of rotation. The composition face made vertical and parallel to a nicol and rotated on a horizontal axis normal to it under the same condition birefringence colour of the adjacent lamellae of a normal twin also change, but the rise and fall together. The information reveals the exact position of a normal twinning axis and limits the parallel or complex twinning axis to one plane.

6) In Parallel of complex twins the change in interference colour of adjacent lamellae may be used to locate the twinning axis. When the interference colour of vertical assuming as in 2 above that position on a horizontal axis which is perpendicular to a nicol. The same is true of composition faces 450 to a nicol.

7) The usual type of twinning in monoclinic feldspar is Carlsbad twinning.8. Albite, Manebach and Baveno twin are found in triclinic feldspar. 


\section{Acknowledgement}

Corresponding Author are grateful to the Principle Investigator Dr. R. S. Kumar, DST-SERC Fast track Young scientist Project, Govt. of India for financial support.

\section{References}

[1] Buerger, MJ. (1945) the genesis of twin crystals. American Mineralogist, 30, 469-482.

[2] Gorai, M. (1951) Petrological studies of plagioclase twins. American Mineralogist, 36, 884-90.

[3] Dowty, E. (1980) Atomic structure of Carlsbad and Carlsbadalbite twins in feldspar. Zeitschrift Kristallographie, 152, 201206.

[4] Brown.WL and Macaudiere, J (1986) Mechanical twinning of plagiclase in a deformed Meta anorthosite: The production of M-twinning. Contributions to Mineralogy and Petrology, 92, 44-56.

[5] Amitabha S, Mihar Bose K. (1987) Geology of Kadavur complex, Tamilnadu, Recent researches in geology 13: 97-107.

[6] Wooster, W.A. (1981) Atomic arrangements on the twin boundaries of orthoclase twins. Mineralogical Magazine, 44, 351-353.

[7] Tobi, A.C. (1962) Characteristic patterns of plagioclase twinning. Norsk geol. Tidsskr, 42-2, 264-271.

[8] Tobi, A.C. (1987) Recognition of plagioclase twinning at significant rock property.proc. Koninkiijke Nederlands Akad. Van Watenschappen 65(4), ser.B.pp.576-581.

[9] Suwa, K. (1956) Plagioclase twinning in Ryoke metamorphic rocks from the Mitsue-mura area, Kii peninsula, central Japan. Jour. Earth Sci., Nagoya Univ., 4, 91-122.

[10]Suwa, K., Mizutani, S. and Tsuzuki, Y. (1974) Proposed optical method of determining the twinning laws of plagioclase. Mem. Geol. Soc. Japan, no. 11, 167-250

[11]Smith, J.V. (1974) Feldspar Minerals 2 (Chemical and Textural Properties). Springer-Verlag, 690p.

[12]Ross, J.V., (1957) Combination of twining in plagioclase feldspars .American Journal of Science.Vol.225, pp.650-655. 